\title{
From skepticism to openness: a qualitative narrative analysis of medical students' attitudes following an integrative medicine course
}

\author{
Eran Ben-Arye ${ }^{1,2} \circledast$ - Adi Finkelstein ${ }^{3,4} \cdot$ Noah Samuels $^{5} \cdot$ Dina Ben-Yehuda ${ }^{4} \cdot$ Elad Schiff $^{1,6} \cdot$ Shmuel Reis $^{4}$. \\ Lior Lesser ${ }^{4} \cdot$ Michael Bergel $^{4} \cdot$ Dorith Shaham ${ }^{4}$
}

Received: 4 November 2021 / Accepted: 30 January 2022 / Published online: 10 February 2022

(c) The Author(s), under exclusive licence to Springer-Verlag GmbH Germany, part of Springer Nature 2022

\begin{abstract}
Objective The present study aimed to explore attitudes of medical students following a course in integrative medicine (IM) focused on palliative and supportive cancer.

Method Attitudes to IM among pre-clerkship medical students were assessed following a 3-day required course, which included interviews with international experts in IM and "hands-on" workshops mentored by IM and non-IM healthcare professionals. Student reflections were analyzed qualitatively, and written narratives were examined thematically.

Results Of 161 students, $102(63.4 \%)$ provided post-course reflections. The main narrative themes included pre-course attitudes, attitude changes and influencing factors, and insights on implementing IM in clinical practice. Pre-course attitudes were predominantly skeptical, with post-course attitudes more open and non-judgmental, addressing research on IM effectiveness and safety. Students looked favorably on the implementation of IM in clinical practice and felt the course enhanced communication with patients.

Conclusions Student attitudes to IM shifted following the course, from a skeptical to a more non-judgmental and accepting approach. IM course may facilitate a better understanding of the limitations and risks of IM practices, particularly in the supportive cancer care setting, as well as implications regarding students' own resilience and professional growth.
\end{abstract}

Keywords Integrative medicine $\cdot$ Integrative oncology $\cdot$ Supportive care $\cdot$ Medical education $\cdot$ Palliative care $\cdot$ Complementary alternative medicine

Eran Ben-Arye and Adi Finkelstein should be considered as cofirst authors, based on their equal and significant contribution to this study

\section{Eran Ben-Arye}

eranben@netvision.net.il

1 Faculty of Medicine, Technion - Israel Institute of Technology, Haifa, Israel

2 Integrative Oncology Program, Clalit Health Services, \& Carmel Medical Centers, LinHaifa, Zebulun, Israel

3 Faculty of Life and Health Sciences, Jerusalem College of Technology, Jerusalem, Israel

4 Faculty of Medicine, Hadassah-Hebrew University Medical School, Hebrew University of Jerusalem, Jerusalem, Israel

5 Center for Integrative Complementary Medicine, Faculty of Medicine, Shaare Zedek Medical Center, Hebrew University of Jerusalem, Jerusalem, Israel

6 Department of Internal Medicine \& Integrative Medicine Service, Bnai Zion Medical Center, Haifa, Israel

\section{Introduction}

Courses teaching complementary and alternative medicine have been taking place in medical schools across North America and globally since the early 1990s, focusing on challenges in doctor-patient communication [1,2]. As the evidence supporting the effectiveness of these practices has increased over the years, in particular in the oncology and palliative care settings, they are increasingly being integrated into conventional medical practice, a process termed "integrative medicine" (IM). Integration has been most extensive in oncology ("integrative oncology"), with guidelines for IM use in patients with breast cancer endorsed by the American Society of Clinical Oncology (ASCO) [3]. IM can be found in departments of oncology [4], palliative care [5], surgery [6], internal medicine [7], and a wide range of in-patient and community-based clinical settings [8]. 
The increasing presence of IM in clinical practice has led to the understanding of the need to address this subject in medical education [9]. In 2004, the Consortium of Academic Health Centers for Integrative Medicine curriculum guidelines highlighted specific challenges in implementing and evaluating IM core competencies [10]. For the most part, IM courses in medical schools emphasize the contrast between the integrative evidence-based approach with that of alternative practices taking place outside the conventional medical setting [11].

The present study set out to explore the impact of a required course teaching IM communication and researchrelated approach on student attitudes to these practices. Student narratives and reflections were analyzed qualitatively, with written narratives examined thematically.

\section{Methods}

\section{IM pre-clerkship course}

The 3-day IM course (November 22-24, 2020) was part of a required pre-clerkship preparatory program for fourth (of 6) year medical students at the Faculty of Medicine, Hebrew University of Jerusalem, Israel. The program was co-designed and taught with the Faculty of Medicine at the Technion, Haifa, Israel, where an IM teaching program has been taking place for nearly 15 years. Due to restrictions of the Israel Ministry of Health COVID-19 Task Committee, the course was conducted in a "hybrid" (on-line and in-person) format, the latter taking place in small groups of students and mentors, all wearing protective face masks throughout.

\section{Course faculty and content}

Course faculty included 38 healthcare professionals and educators, both with and without IM knowledge and experience. This included 15 physicians from the Hebrew University of Jerusalem and 23 physicians and non-medical IM practitioners (e.g., reflexologists, acupuncturists, etc.) working in the Technion faculty of medicine affiliated integrative clinical settings, including oncology, palliative care, internal medicine, surgery, family medicine, psychiatry, pediatrics, hematology, gynecology, gastroenterology, and pain medicine. The participation of non-IM physicians was believed to enhance workshop discussions, exposing students to attitudes of conventional physicians to IM in their clinical settings.

The course included 5 "hands-on" workshops, during which mentors and students learned about and experienced various IM modalities and integrative clinical therapeutic settings. IM modalities included traditional herbal medicine; mind-body therapies (e.g., meditation and guided imagery); manual techniques (e.g., acupuncture, acupressure); movement therapies (e.g., Tai Chi/Chi Gong). Student-directed tasks included pre-recorded lectures and simulated doctorpatient interactions, with students asked to answer short questions about the feasibility of implementing IM-related skills during clinical clerkship training.

Students watched seven pre-recorded videos about traditional herbal medicine in supportive cancer care (from an online "Coursera" course on the subject) [12]; traditional Chinese Medicine; Mind-Body-Spirit medicine; integrating IM in oncology and surgery; implications of IM on student well-being, relief of stress and anxiety; and overcoming challenges facing them related to compassion, resilience, dealing with "burnout," etc. Each video was introduced by a leading IM researcher, clinician, or medical educator. "Live" online interactions included discussions with leading Israeli and international IM physicians and nurses from oncology, internal and pediatric medicine, gynecology, psychiatry, family medicine, neurology, and pain medicine.

\section{Data collation}

Of the 161 students attending the course, $139(86.3 \%)$ provided post-course assessments. Most were female (53.6\%), with a mean age of 25.3 years. Nearly a third (31.4\%) reported prior experience with complementary and alternative medicine, and 102 (63.4\%) provided post-course reflections. Of this sample size of 102 students, 78 provided detailed narratives, which enabled saturation of the themes identified regarding attitudes and reflections on the course content and experience.

\section{Data analysis}

Analysis of the study narratives was conducted manually according to the 6 phases of Braun and Clarke thematic analysis [13]. An inductive approach identified themes strongly linked to the data [14]. In the first three phases (familiarizing yourself with your data; generating initial codes; searching for themes), E.B.A, D.S., and A.F. worked independently and met several times to discuss impressions and reach an agreement. Phase four (reviewing themes) and phase five (defining and naming themes) were assessed by E.B.A and reviewed and refined by D.S. and A.F. Patton's dual criteria for judging categories were followed: internal homogeneity_data within themes which hold together meaningfully; and external heterogeneity - with clear and identifiable distinctions between themes. The final report (phase 6) was reviewed by all team members. 


\section{Ethical considerations.}

The study protocol was submitted to and approved by the Hebrew University of Jerusalem Faculty of Medicine Ethical Committee (approval number: 23052021).

\section{Results}

Qualitative analysis of post-course student narratives identified three predominant themes (Table 1): pre-course attitudes to complementary and alternative medicine; changing attitudes related to learning about IM and its modalities, and influencing factors; insights into the implementation of IM in clinical practice. The change in the students' attitude to IM was assessed using only post-course narratives, as pre-course narratives were not available for analysis.

\section{Theme 1: Pre-course attitudes to complementary and alternative medicine: from skepticism to openness}

Pre-course attitudes toward complementary and alternative medicine were reported retrospectively by the students. These were frequently skeptical and emphasized the lack of research and quality control. Some students questioned the popularity and widespread use of these practices among patients despite the lack of supporting evidence. Student attitudes ranged from curiosity to prejudice ("I came to the course with a relatively judgmental, fixed, and outdated attitude"), and in some cases, antagonism ("an attitude which

Table 1 Main themes identified from post-course student narratives from and narratives

\begin{tabular}{ll}
\hline Themes & $\begin{array}{l}\text { The student's affinity, inspiration, or/and health- } \\
\text { belief regarding CAM }\end{array}$
\end{tabular}

Pre-course attitudes*

Affinity with the more rational nonmystical aspects of the Jewish religion

Attitude change during the course

Affinity with traditional herbal Arab medicine

\section{Post-course clinical insights}

Relatedness to the aunt's CAM- affiliated healthbelief model along her journey in the oncology wards
Despite the fact that I am a religious person, I am more connected to the rational and philosophical aspects of religion, less to the spiritual and mystical aspects. The education I received in Academia in general, and specifically in medical school, made me wary of the content of the course, and I approached with an attitude of "know your enemy."

In the traditional society in which I was raised, there is a belief that sage can cure everything. Every time my stomach would hurt, herbal remedies were my second-best friend. Having said that, before the course, I was very skeptical about the need for the CAM course within our "conventional" medical studies, and I felt that we do without it... I never imagined that Integrative Medicine is a whole of itself, and I was surprised to discover the amount of research in existence on different subjects since I believe in evidence-based medicine, and I was familiar with only a small number of studies showing its effectiveness in pain relief

What is most important in my eye: we need to be very modest, very humble. At the end of the day, my aunt got better. She went on her own path and beat her cancer... she lived with her family for 5 years after being diagnosed, even though not all of those were quality years... we should not think that we know it all, even if we have acquired much knowledge. We need to keep an open mind regarding other opinions and approaches. My aunt's brother, a senior physician, eulogized her at the funeral: "you spoke a different language than me, one which I couldn't understand and couldn't connect to. But because of you, I was able to include and accept." I hope that as a doctor I will always be able to listen, to learn, to include, to accept. And through all these, to communicate

\footnotetext{
${ }^{*}$ Pre-course attitudes regarding complementary and alternative medicine were reported retrospectively by the students (see text)
} 
was suspicious and hostile"). The therapies were often perceived as unfamiliar and vague ("Anything related to non-conventional medicine was considered by me as something 'naturopathic,' and nothing more"), contradicting conventional medicine and unable to be researched ("I was skeptical as to whether it was possible to investigate complementary medicine, and whether it was of any benefit"). Their effectiveness was perceived as no more than a placebo effect, with practitioners often taking advantage of patient desperation ("people who are looking to make money off of weak populations; and that there is no real basis behind the entire concept").

At the same time, a number of narratives looked favorably on complementary and alternative medicine. While still considered a placebo, they were also perceived as empowering the patient ("additional therapeutic option allowing the patients to feel they fight their disease on all fronts, but not as a real treatment"), working within a positive context of faith and personal experience:

"I came extremely skeptical regarding these subjects since I felt that many of them have no research-based foundation, and most work through the power of faith."

Many whose attitude was negative and dismissive hoped the IM course would provide tools supporting their approach ("knowing your enemy"). They saw themselves as "on the side" of conventional medicine, with "the others" described as "mainly people who were more 'spiritual'... those who don't believe in Western medicine... who are also opposed to vaccinations." Only a minority of students adopted a more "cautious but open approach" based on their limited knowledge and experience with these practices.

\section{Theme 2: Attitude changes related to learning about IM and its modalities, and factors influencing changes in attitude}

Post-course narratives showed a shift in attitudes, from a separation between "us" and "them," as a "journey" taking place during the course:

"I cannot say that I had an experience which changed my life 180 degrees. But I did understand that perhaps there is a place for complementary medicine therapies... I was given the opportunity to be exposed to these concepts, even if it might take years until I will decide to implement them myself."

For most students, post-course attitudes viewed IM less as a single discipline ("I now understand that not all of the disciplines of alternative medicine are cut off") and more consistent and evidence-based. The presentation of the research on IM was an important factor influencing attitudes ("I was exposed to new and interesting material, which changed my approach to the subject and assuaged my judgmental attitude").

Other influencing factors included the participation of IM-trained physicians and other medical professionals in the "hands-on" workshops. They were seen by students as "medical and scientific professionals" who "speak medical and anatomic terminology." For many students, the IM professionals served as role models, "treat(ing) with their hearts, and not just their heads" and "who I believe and feel closer to their way of life."

Participation of non-medical IM practitioners helped promote the change in attitude, especially during self-reflection and with modalities such as guided imagery ("I reached a true level of tranquility"). Workshops were often intensely emotional-spiritual ("a powerful experience which brought me into places in my soul where I don't invest enough") and perceived within the context of the students' own personal and professional growth ("my growth as an individual in acquiring tools, abilities, and understanding").

Changes in attitudes varied greatly, with some describing a gradual, step-wise process. "Their speech and the language were different, and the world in which they approach helping patients was different. In the beginning, it aroused resistance, and I approached the interaction as 'know thy enemy.' Later, it became 'if you can't beat them, join them,' and as the workshop progressed, more 'I want this,' as opposed to 'I must do this'."

For others, "the penny dropped" after listening to patients describe their experiences with IM:

"I could not remain indifferent to the testimony of oncology patients stating that if it weren't for the alternative medicine treatments, they would not have been able to undergo the conventional medical treatments."

Still, for others the change in attitude was more gradual, accompanied by a feeling of "re-connectedness" with concepts with which they were familiar before entering medical school:

"I didn't feel that I had been exposed to something that I had never considered before, and it is possible that for this reason, after few lessons in the course, I felt a sudden surge of simple understanding of the goingson, as if all I needed was for the penny to drop."

The process was frequently accompanied by a more open and less judgmental approach to IM: "Participating in the course, especially before my entrance into the hospital wards, cleansed me from a significant slice of being judgmental, and will allow me to learn and grow with a kind of medicine which is a little more accepting."

The ability to be "clean" from pre-conceptions and prejudices was mentioned regarding communication with patients 
("being able to have a 'clean' approach to the patient who reports that she is using herbal remedies").

At the same time, the need for scientific skepticism was maintained: "I learned to be open with respect to modalities with which I am unfamiliar, while at the same time not to abandon the need to be careful when assessing the source of the information being provided." Safety-related issues regarding IM were perceived within the conventional medical context: "I understood that we were talking about medications and compounds with significant effects on the body, and as such can cause side effects, making their use dangerous."

Finding a balance between openness and critical thinking was seen as a significant challenge during the course: "My challenge throughout the course was to find the point of balance between an open and a critical approach-a point which I know that I have not yet reached."

\section{Theme 3: Insights into the implementation of IM in clinical practice}

Post-course narratives also addressed students' perception of the feasibility of implementing IM-related skills during their clinical clerkship training. They identified the need for " $a$ new language... a new world which has been opened to us."

Students also recognized the need for conventional medicine to work in synergy with IM.

"To create a change within the boundaries of conventional medicine and to spread the message of integrative medicine throughout the land. To try to introduce different types of medicine - to turn 'alternative medicine' to 'complementary medicine... so that there is no conflict between them...only synergy'."

Communication with patients about IM was accompanied by the need for a non-judgmental, even if skeptical, approach: "to approach the patient who is using complementary medicine in a more accepted and directed way... to know the right questions to ask". They encouraged open discussion with patients about IM, respecting their autonomy and their right to hold their own health beliefs: "I hope that as a doctor I will always be able to listen, to learn, to include, to accept. And through all these, to communicate."

Many students saw themselves incorporating IM in their clinical training and medical practice: "...providing an eclectic solution to my future patients." Attitudes and skillrelated domains overlapped with the enhancement of patientcentered care ("to convey to patients that I care about them, and look at them holistically") and shared decision-making "based on trust between therapist and patient." These were important facets to address when taking a medical history:
"I was very impressed with the approach to the anamnesis and the approach to the patient as a whole. Taking his needs into consideration, giving an ability to express what is missing in regular medicine."

The IM-centered history was considered an important element of clinical practice, as were IM research-related and analysis of the findings (for and against).

"It is my hope that when I become a doctor, I will have the courage to leave my comfort zone and research other lines of treatment as well."

A number of students expressed an interest in furthering IM treatment-related skills during clinical practice: “... as the opening of a window to a world in which I wish very much to take part in the future... hopefully incorporating in clinical practice.... Integration can take place in any number of ways... in simple gestures in the clinic."

Workshops were found by many to promote their own well-being, especially when addressing emotional and stress-related concerns. The "hands-on" experience was felt to enhance resilience as well:

"The exercise in mindfulness was very significant for me. I felt that the relaxation techniques which were being taught could help me deal in the future with the stresses associated with the medical profession."

Self-practiced IM techniques were believed to help prevent "burnout" and relieve anxiety and pain.

"I will be taking with me the pressure points that we learned, which can perhaps help me personally with pain before I take medication...relaxation exercises and breathing, and the importance of touch."

Specific outcomes such as stress relief were accompanied by insight into the student's professional "journey" ahead, with years of training before becoming physicians and healers:

"The idea of looking at me as a person, as a therapist, as a doctor, is very lacking during our studies. The meeting with this idea was fascinating and wonderful-it brought me back to questions... about finding a balance between our personal lives, the profession I am striving for as a therapist, and my place in the world."

\section{Discussion}

The qualitative study of the required IM "hybrid" course found a change in attitudes, from one of skepticism to complementary and alternative medicine practices to a more open and non-judgmental approach to evidence-based IM 
and its implementation in a wide range of conventional medical settings. The attitude change was accompanied by an increased awareness regarding the risks and challenges associated with these practices. It reflected the goals of the course, which included teaching IM-related communication and research-related skills while encouraging a balance between skepticism and openness within a commitment to both science, practitioner, and patient health.

A number of influencing factors were found to promote a more open and accepting attitude toward IM. These included enhanced skills for researching the effectiveness and safety of these practices while at the same time addressing patient needs and health-belief models. Other factors included the participation of IM-trained physicians and practitioners with non-IM physician mentors from a wide range of disciplines; the former incorporating IM in their clinical practice of medicine; the latter ensuring a more objective and questioning perspective during workshop discussions. IM practitioners (e.g., acupuncturists) working in integrative settings (e.g., surgery) were able to share their knowledge and experience while addressing the students' own concerns (e.g., pain) and well-being. These factors facilitated the intention of many students to include IM during their clinical clerkship training as well as in their future work as physicians.

The implications of the attitude change and intention to include IM in clinical training and practice are important. Firstly, communication on the use of complementary and alternative medicine is needed in order for medical professionals to help their patients make an informed decision on the benefits and risks of these practices [15]. Secondly, the course raised awareness among students who will now see patients using these therapies not as "anticonventional" but as "the other person," one with their own health-belief model [16]. Finally, the acquisition of IM-related skills will allow them to discuss these practices in a more open and accepting environment (vs. dismissive and judgmental), enhancing the shared-decision process with a patient-centered approach.

The IM course was also found to have an impact on student-perceived resilience and personal growth, aspects of IM education addressed by Haramati and colleagues [17]. It should be noted, however, that mind-body modalities such as mindfulness and meditation are increasingly becoming part of the teaching curriculum in the promotion of resilience among medical students. Examples of this can be seen at the faculty of medicine at the University of Toronto, Canada [18]; and across a wide range of teaching settings for nurses [19]. At the University of New Mexico School of Medicine, the disciplines of integrative medicine, palliative care, and cultural awareness are considered among the 12 cross-cutting themes being incorporated into the school of medicine curriculum [20]. In the present study, the "handson" workshops, during which students experienced the preparation of herbal medicinal recipes; the "de-Qi" sensation of an acupuncture needle; or the deep relaxation during breathing exercises, were most likely significant factors affecting their introduction to IM care. For many, it was the actual experience of an IM intervention that brought to a change in attitude. This experience aroused both curiosity and mindfulness, allowing students to grasp the context of IM care beyond the evidence supporting their effectiveness for treating specific outcomes.

The present qualitative study has a number of limitations, which include the use of short narratives as opposed to extensive in-depth interviews to identify health beliefs, as well as prior experience with complementary and alternative medical therapies. A more long-term follow-up is needed, examining evolving attitudes and implementation of IM-related skills during the clinical clerkship years. Future research will also need to explore other medical education programs in countries and settings, which will test the generalizability and the cross-cultural significance of the findings presented.

In conclusion, the "hybrid" IM course was shown to lead to a change in attitudes among medical students toward IM, from one of skepticism about complementary and alternative medical practices to a more non-judgmental and accepting approach to IM. This change in attitude was accompanied by a better understanding of the limitations and risks of these practices, with implications regarding the students' own resilience and professional growth. Further research will need to examine long-term changes in the students' attitudes during their clinical clerkship.

Acknowledgements The authors wish to thank all of the mentors and instructors who participated in the course and shared their extensive knowledge and experience with the students, significantly enhancing the educational process:

*Faculty of Medicine, Hebrew University of Jerusalem: Dr. Shunit Armon, Dr. Betla Falah, Dr. Ittamar Gork, Prof. Sorina GrisaroGranovsky, Dr. Guy Kalmanovich, Dr. Fadi Kharouf, Dr. Liron Kogan, Dr. Gisele Ovadiah, Dr. Shani Paluch-Shimon, Dr. Hagit Peleg, Dr. Gilat Reich, Dr. Tali Sachar, Dr. Efrat Suraqi, Dr. Martine Toledano, and Dr. Yuval Yishai;

*Faculty of Medicine, Technion, Haifa: Olga Agur, Dr. Shmuel Attias, Dr. Zahi Arnon, David Avshalomov, Dr. Erez Baruch, Dr. Yulia Bronstein, Assaf Ezra, Galit Galil, Sagi Gavrieli, Dr. Orit Gressel-Raz, Dr. Ilana Levy, Tsach Nachumi, Raviv Peleg, Avigail Sagee, Sagi Shalev, Danny Steinberg, and Daphna Wolf;

Online lecturers and presenters, Israel: Dr. Zachi Arnon, Dr. Meron Barak, Yael Barak, Prof. Moshe Frenkel, Dr. Rafi Goldman, Prof. Ofer Lavie, Lily Perlman, Liora Preis, Dr. Alon Reshef, Dr. Yaron River, Tuviah Scott, Dr. Galiah Shtoffman, and Pessi Israely. International: Prof. Adi Harama0ti (U.S.), Dr. Emanuela Portalupi (Italy), and Dr. Catherine Zollman (UK).

Author contribution EBA, AF, ES, LL, and DK organized the trial and collected the data analyzed in this study. EBA, ES and NS, AF, and DS planned the study. EBA, AF, and DS carried out the analysis and wrote a draft manuscript. All authors participated in the revision of the manuscript. 
Funding The 7 videos produced for the course were jointly funded by the Hebrew University Hadassah School of Medicine in Jerusalem and the Rappaport Faculty of Medicine, Technion Institute of Technology, Israel.

Data availability Data transparency is available pending request from the submitting author.

\section{Code availability N/A.}

\section{Declarations}

Ethics approval The study protocol was submitted to and approved by the Hebrew University of Jerusalem Faculty of Medicine Ethical committee (Approval number: 23052021).

Consent to participate Participation in this study was voluntary and verified by participants' consent.

Consent for publication All authors consented for publication of the present manuscript.

Conflict of interest The authors declare no competing interests.

\section{References}

1. Frenkel M, Ben AE (2001) The growing need to teach about complementary and alternative medicine: questions and challenges. Acad Med 76(3):251-254. https://doi.org/10.1097/00001888-20010 3000-00012

2. Pearson NJ, Chesney MA (2007) The CAM education program of the national center for complementary and alternative medicine: an overview. Acad Med 82(10):921-926

3. Lyman GH et al (2018) Integrative therapies during and after breast cancer treatment: ASCO endorsement of the SIO clinical practice guideline. J Clin Oncol 36(25):2647-2655

4. Toledano A, Rao S, Frenkel M, Rossi E, Bagot JL, Theunissen I, Díaz-Sáez G (2021) Integrative oncology: an international perspective from six countries. Integr Cancer Ther 20:15347354211004730. https://doi.org/10.1177/15347354211004730

5. Mattai SAD, Hui KP (2021) Reframing palliative care: an east-west integrative palliative care model. Chin J Integr Med 27(10):723728. https://doi.org/10.1007/s11655-021-3500-9

6. Schiff E, Attias S, Hen H, Kreindler G, Arnon Z, Sroka G, Ben-Arye E (2012) Integrating a complementary medicine service within a general surgery department: from contemplation to practice. J Altern Complement Med 18(3):300-305. https://doi.org/10.1089/acm. 2011.0564

7. Witt CM, Pérard M, Berman B, Berman S, Birdsall TC, Defren H, Kümmel S, Deng G, Dobos G, Drexler A, Holmberg C, Horneber M, Jütte R, Knutson L, Kummer C, Volpers S, Schweiger D (2015) Using the framework of corporate culture in "mergers" to support the development of a cultural basis for integrative medicine - guidance for building an integrative medicine department or service. Patient Prefer Adherence 19(9):113-120. https://doi.org/10.2147/ PPA.S66778
8. Vitek SM, Bhagra A, Erickson EE, Cutshall SM, Slack SM, Rodgers NJ, Smidt JM, Jordan MJ, Bauer BA, Chon TY (2021) Optimizing delivery to meet demand for integrative medicine services in an academic hospital setting: a pilot study. Explore (NY) 17(4):340-343. https://doi.org/10.1016/j.explore.2020.03.001

9. Zick SM et al (2018) Integrative oncology scholars program: a model for integrative oncology education. J Altern Complement Med 24(9-10):1018-10220

10. Kligler B, Maizes V, Schachter S, Park CM, Gaudet T, Benn R, Lee R, Remen RN; Education working group, consortium of academic health centers for integrative medicine. Core competencies in integrative medicine for medical school curricula: a proposal. Acad Med. 2004 79(6):521-31. https://doi.org/10.1097/00001888-20040 6000-00006.

11. Maizes V, Schneider C, Bell I, Weil A (2002) Integrative medical education: development and implementation of a comprehensive curriculum at the University of Arizona. Acad Med 77(9):851-860. https://doi.org/10.1097/00001888-200209000-00003

12. Ben-Arye E, Samuels N. Traditional herbal medicine in supportive cancer care: from alternative to integrative. coursera online teaching platform. https://www.coursera.org/learn/cancer-medicine-alter native-herbal-asia. Accessed: December 28, 2020.

13. Braun V, Clarke V (2006) Using thematic analysis in psychology. Qual Res Psychol 3(2):77-101

14. Patton MQ.Qualitative evaluation and research methods (2nd ed.). 1990. Newbury Park, CA: Sage.

15. Ben-Arye E, Samuels N, Goldstein LH, Mutafoglu K, Omran S, Schiff E, Charalambous H, Dweikat T, Ghrayeb I, Bar-Sela G et al (2015) Potential risks associated with traditional herbal medicine use in cancer care: a study of Middle Eastern oncology health care professionals. Cancer 122:598-610

16. Ortiz M, Teut M, Ben-Arye E, Reshef A, Kaffman M, Arnon Z, Stöckigt B, Bähr V, Meoded-Danon L, Brinkhaus B, Schiff E (2018) Can complementary medicine enhance doctor-patient communication skills? Insights from an international medical student project. Complement Ther Med 41:283-286

17. Elder W, Rakel D, Heitkemper M, Hustedde C, Harazduk N, Gerik S, Haramati A (2007) Using complementary and alternative medicine curricular elements to foster medical student self-awareness. Acad Med 82(10):951-955. https://doi.org/10.1097/ACM.0b013 e318149e411

18. Kulman-Lipsey S, Yang S, Pedram Javidan A, Fung B, Levinson A, Vernon J, Nickell L, Leo J (2019) An integrative longitudinal resilience curriculum. Clin Teach 16(4):395-400. https://doi.org/ 10.1111/tct.13054

19. van der Riet P, Levett-Jones T, Aquino-Russell C (2018) The effectiveness of mindfulness meditation for nurses and nursing students: an integrated literature review. Nurse Educ Today 65:201-211. https://doi.org/10.1016/j.nedt.2018.03.018

20. Kitzes JA, Savich RD, Kalishman S, Sander JC, Prasad A, Morris CR, Timm C (2007) Fitting it all in: integration of 12 crosscutting themes into a School of Medicine curriculum. Med Teach 29(5):489-94. https://doi.org/10.1080/01421590701288564

Publisher's note Springer Nature remains neutral with regard to jurisdictional claims in published maps and institutional affiliations. 